Staff Working Paper/Document de travail du personnel 2020-1

Last updated: January 9, 2020

\title{
Contagion in Dealer Networks
}

by Jean-Sébastien Fontaine and Adrian Walton

Financial Markets Department

Bank of Canada, Ottawa, Ontario, Canada K1A 0G9

jsfontaine@bank-banque-canada.ca, awalton@bank-banque-canada.ca

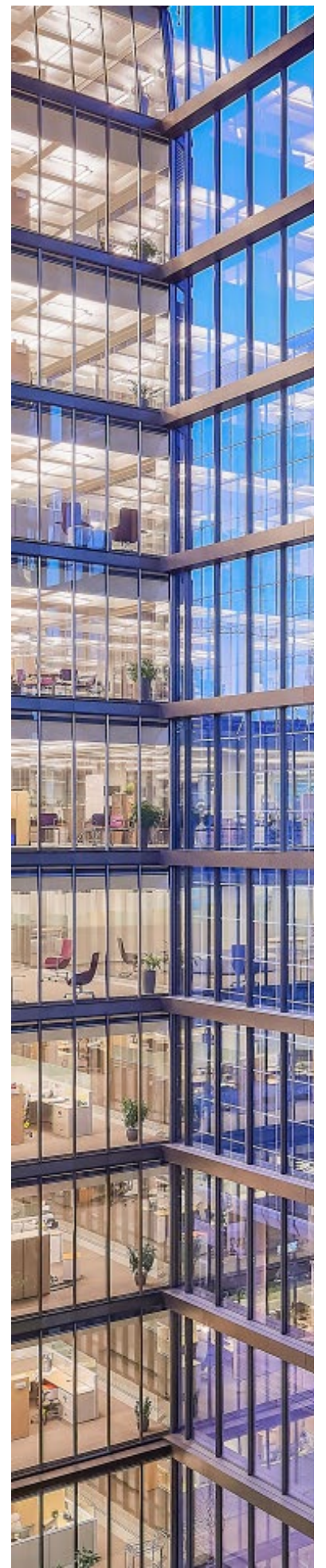

Bank of Canada staff working papers provide a forum for staff to publish work-in-progress research independently from the Bank's Governing Council. This research may support or challenge prevailing policy orthodoxy. Therefore, the views expressed in this paper are solely those of the authors and may differ from official Bank of Canada views. No responsibility for them should be attributed to the Bank. 


\section{Acknowledgements}

We are grateful for comments and suggestions from Sébastien Bétermier, Darrell Duffie, Ryan

Riordan, Norman Schürhoff, Toni Whited, as well as Jason Allen, Léanne Berger-Soucy, Narayan

Bulusu, Sermin Gungor, James Hately and Maksym Padalko. 


\section{Abstract}

Dealer networks provide essential intermediation services in over-the-counter markets. We document the response of dealer networks to the arrival of new public information. We find that after public news releases, dealer networks become more complex and channel larger flows of securities between buyers and sellers. These effects are concentrated in bonds that were more actively traded and had more-complex dealer networks. One natural interpretation is that dealer networks become more complex after the news releases to accommodate shifts of intermediation demand. For these bonds, following the news releases, we also document more frequent and larger contagion of settlement fails over the network. The evidence points to a trade-off. Settlement fails allow for contagion of counterparty risk in dealer networks; yet, allowing for fails provides dealers greater flexibility to accommodate shifts in demand for intermediation.

Bank topics: Financial markets; Payment clearing and settlement systems; Market structure and pricing

JEL codes: E4, G1, G2, G21, L1, L14 


\section{Introduction}

Networks of dealers operate in large over-the-counter (OTC) markets where trading is bilateral and decentralized. These networks can overcome search and informational frictions to intermediate trades between buyers and sellers (see, e.g., Duffie, 2011). Using granular data on trading activity, an emerging empirical literature has documented the structure of dealer networks and their role in the intermediation of financial markets. For instance, Li and Schürhoff (2019) show that peripheral investors in the US municipal bond market pay a markup to get faster execution times by transacting with dealers with a more central position in the network.

We show how dealer networks change after the arrival of new information. Based on a unique and granular dataset for the Canadian government spot and repo bond market, we find that after the release of new economic data, dealer networks intermediate a larger volume of trades between end investors. The effect is concentrated in the most actively traded and liquid bonds, where dealer networks are more complex. We find that these networks expand and become even more complex, which is consistent with providing immediacy to end investors. The evidence shows how the arrival of new information shifts investors' demand for intermediation and changes the complexity of dealer networks for the most liquid bonds.

After the news releases, we find that these bonds also exhibit more frequent and more severe contagion of settlement fails across their networks of dealers. Settlement fails are unanticipated delays in settlement that occur when counterparties fail to deliver securities in spot or repo trades. In many OTC markets, contracts that govern bilateral trades are flexible regarding the delivery of securities against cash. If a settlement fails on the scheduled date, then the settlement is, by convention, delayed and attempted again the next day, and the terms of the trade remain unchanged. ${ }^{1}$

\footnotetext{
${ }^{1}$ Some markets may include an explicit penalty for failing to deliver. For example, the US Treasury market (Garbade et al., 2010).
} 
Our evidence on dealer networks and contagion, together, suggests that allowing settlement fails involves a trade-off. If fails were treated as contractual defaults, then dealers would only sell securities they currently held, limiting their ability to provide immediacy. However, allowing for the contagion of fails means that a higher level of counterparty risk must be tolerated. ${ }^{2}$ Contagion in the network also means that a substantial degree of externality is tolerated; how each dealer manages counterparty risk influences the likelihood and severity of contagion. While this risk may typically be benign, counterparty risk can sometimes rise rapidly and severely hinder intermediation. Garbade et al. (2010) show that daily settlement fails in the US Treasury market averaged above $\$ 200$ billion and often exceeded $\$ 350$ billion for several weeks after the 2008 Lehman Brothers insolvency. They also describe several policy responses that were taken to alleviate settlement fails. ${ }^{3}$

Our data include detailed proprietary and regulatory information about all spot and repo trades in the market for Government of Canada bonds, including information about counterparties. We use the counterparty identification in our dataset to construct a directed network of settlement exposures between counterparties for each bond and each day where the direction of the link between two counterparties is determined. This produces more than 17,000 observations of dealer networks with large time series and cross-sectional variation. For each network, we compute several standard network measures of the length and number of a network's directed paths. As a summary metric of these metrics, we compute their first principal component, Complexity. ${ }^{4}$ The COMPLEXITy of dealer networks is associated with bonds that have benchmark status, more trading activity and scarcity in the repo market. ${ }^{5}$

\footnotetext{
${ }^{2}$ Counterparty risk arises because, in case of a default, market participants would face market risk as they search for a new counterparty to establish equivalent trades.

${ }^{3}$ The Federal Reserve initially relaxed the terms of its securities-lending program, the US Treasury reopened several off-the-run Treasury notes and the Treasury Market Practices Group adopted changes in market practices.

${ }^{4}$ COMPLEXITY is the first principal component of the number of links, the number of paths, the average path length, and the length of the longest path in a network.

${ }^{5}$ Analogous to on-the-run treasuries in the US, BENCHMARK bonds are the most liquid and active bonds in our sample.
} 
These networks involve a complex combination of spot and repo trades, where the latter serve to fund long positions or cover short positions. Other, older, less actively traded and less liquid bonds exhibit dealer networks with low Complexity. We also compute Network Volume, the sum of the net settlement volume across a network. NeTwork Volume is a proxy for intermediation quantity, which is different than trading volume because of netting that takes place between counterparties.

Our first set of results follow from an event study of dealer networks around the release of key economic data. ${ }^{6}$ For BenchmaRK bonds, which are the bonds with the most complex dealer networks, we find that COMPLEXITY increases by around 0.4 standard deviations following the news, on average. We also find that the NeTwork Volume increases by $\$ 750 \mathrm{M}$, on average, or around 0.25 standard deviations. If we look at a larger set of bonds with high the COMPLEXity as measured days before the news, we find that the ComplexITY increases by 0.25 standard deviations and the NETWORK Volume increases by $\$ 225 \mathrm{M}$. The increases for other bonds are much smaller or insignificant. One interpretation of the results is that the COMPLEXITY of dealer networks increases around news releases to accommodate more demand for intermediation in the most liquid or active bonds. The evidence is consistent with seminal work showing that the arrival of public information can set up episodes where there are large changes in prices, trading volumes and volatility (Ederington and Lee, 1993; Fleming and Remolona, 1999). The evidence may also be due, at least in part, to higher learning-by-trading activity, either by clients or by dealers, as suggested in Brancaccio et al. (2017).

Our second set of results focuses on the contagion of settlement fails. We begin by documenting some stylized facts that help establish the connection between settlement fails and dealer networks. First, fails in repo and spot markets are closely related, consistent with dealer networks relying on both markets and with fails in each market contaminating

\footnotetext{
${ }^{6}$ We focus on the release of news on GDP, unemployment, retail sales and inflation as well as the release of monetary policy announcements.
} 
the other market. Second, the distribution of fails exhibits a fat tail with clusters of large fail volumes. This is consistent with the idea of contagion as fails cascade through dealer networks. The average share of settlement volume that fails is only 0.5 percent, but it frequently spikes to as much as 10 to 20 percent. Fleming and Garbade (2005) describe these spikes as "daisy chains" of fails cascading through a network. Third, to emphasize the idea that fails are connected, we simulate fails in the population of observed trades from two distributions: one where fails occur uniformly at random and independent of one another, and another where fails are correlated. We show that correlation between fails is needed to match the fat tail and the mass of observations of zero fails.

Next, we ask whether fail contagions are more severe after news releases. We find that the size of the tails increases substantially in the distribution of fail volumes. For BENCHMARK bonds, the increase in fails is $\$ 400 \mathrm{M}$ and $\$ 2,000 \mathrm{M}$ at the 95 th and 99 th percentile, respectively, which corresponds to increases of 1 and 5 standard deviations in the full sample. For the larger set of bonds with high COMPLEXITy, the increase is $\$ 170 \mathrm{M}$ and $\$ 530 \mathrm{M}$ at the 95th and 99th percentile, respectively. The effect is highly non-linear: the increase in fails at the 99th percentile is more than two times the increase in the NETwORK VoLume, both for the BEnCHMARK and the high-COMPLEXITy bonds. The increases are much smaller or insignificant for other bonds. One simple interpretation is that the complexity of a dealer network increases the probability of contagion beyond the simple effect of the larger volume. In other words, network complexity mediates the causal effect of news on settlement fail contagion.

We verify that the increase in fails does not align with the prediction that the likelihood of contagion increases mechanically based solely on the higher settlement volume. We consider a baseline quantile regression targeting the 95th percentile, including controls for the settlement volume, market liquidity, scarcity in the repo markets and bond characteristics. The coefficient estimate for COMPLEXITY is positive and significant. It also subsumes the 
effect of Network Volume and the Benchmark dummy, providing further evidence that COMPLEXITY mediates the causal effect of news on fails.

We use reduced-form regressions to measure the strength of the relationship between CompleXity and contagion across the full sample. We estimate that an increase of ComPLEXITY from its first to last sample decile increases the probability of FAILS occurring from close to 20 percent to around 40 percent. We also estimate that the 90th, 95th and 99th percentiles of the size of FAILs (conditional on some fails) increase by $\$ 50 \mathrm{M}, \$ 120 \mathrm{M}$ and $\$ 135 \mathrm{M}$, respectively. These estimates are large, significant and robust to using individual network metrics, to including bond characteristics or fixed effects, and to including controls for the trading activity and the scarcity of the bonds, two known determinants of fails (Fleming and Garbade, 2005; Boni, 2006). In fact, COMPLEXITY is the strongest determinant of FAILS in this exercise.

We perform two final tests, motivated by other work on dealer networks. First, we follow Li and Schürhoff (2019) who find that clients pay a "centrality premium" in exchange for greater immediacy. We also find that clients tend to pay a higher mark-up when they are less central in a network or if they transact with a dealer that is more central in the network. This confirms existing results for a market for government bonds, which is more liquid and has a more complex network. The evidence is consistent with more-central dealers providing greater intermediation benefits to end investors, as in Li and Schürhoff (2019), or with more-central dealers learning more information from their trades, as in Babus and Kondor (2018).

Next, we ask whether the presence of a central clearing counterparty $(\mathrm{CCP})$ in this market can mitigate fails. In our sample, a CCP provides novation and netting of inter-dealer trades, but Duffie and Zhu (2011) show that multilateral netting may not effectively reduce exposures through netting if the CCP clears only a fraction of these trades. ${ }^{7}$ To check the effect of

\footnotetext{
${ }^{7}$ Novation may reduce the size and complexity of a network, while margining can reduce counterparty risk.
} 
the $\mathrm{CCP}$ on the network, we run the following counterfactual experiment. Essentially, we disconnect the CCP node from our network, re-assign trades across bilateral links between dealers and recompute all network statistics. The results show that, if anything, the CCP makes the network slightly more complex in practice. The reason is that the CCP creates an additional node between dealers, duplicating the number of links between two dealers when they execute bilateral and centrally cleared trades on the same day.

Our results contribute to an emerging but rich empirical literature on dealer networks in OTC markets. Di Maggio, Kermani, and Song (2017) find that a centrality premium in the US corporate bond market may also include the value of a dealer's advisory services. (See also Bátyi, Parlour, and Rajan 2016). Hollifield, Neklyudov, and Spatt (2017) find evidence of a centrality discount in dealer networks for asset-backed securities, which they attribute to differences in clienteles.

In contrast with equity markets, fail volume is much larger and concentrated in the most liquid and largest bonds. ${ }^{8}$ Empirical work on fixed-income fails is scarce but, in an important work, Corradin and Maddaloni (2019) show in the case of Italian government bonds that purchases by the European Central Bank increase bond scarcity in the repo market and that higher scarcity leads to a higher probability of settlement fails. We confirm that scarcity is a key determinant of the likelihood and quantity of fails.

Theoretical guidance from existing work is thin regarding a trade-off between settlement fails and dealer networks in OTC markets. Khapko and Zoican (2019) analyze a closely related trade-off between settlement speed and market quality. They focus on the optimal contract in a static, two-sided market. Our results suggest that allowing for settlement delays also allows the formation of larger and more-complex networks that intermediate peripheral

\footnotetext{
${ }^{8}$ The literature on settlement fails in equity markets focuses on the interaction with short-selling and a debate persists around the costs and benefits of fails. Raising the costs of fails to reduce counterparty risk may limit short-selling and reduce liquidity and price discovery (Evans, Geczy, Musto, and Reed 2009; Fotak, Raman, and Yadav 2014; Liu, McGuire, and Swanson 2017). However, high levels of fails could result in mispricing and increased volatility (Stratmann and Welborn 2012; Autore, Boulton, and Braga-Alves 2015).
} 
bond investors. Hence we contribute evidence of a trade-off between the intermediation benefits provided to clients in dealer networks, on the one hand, and settlement fails, on the other hand, which can channel counterparty risk across the dealer network. ${ }^{9}$

Agents' limited commitment to fulfill their obligations underpins settlement fails. Repeated interactions can overcome this friction (Allen and Gale, 1999), but enforcement depends crucially on the information set of each agent (see, e.g., Di Maggio and Tahbaz-Salehi 2015). In the bond market, it is generally not possible to assign blame or to determine which party is the first to fail. ${ }^{10}$ Babus and $\mathrm{Hu}$ (2017) analyze contracts that are self-enforcing, but contracts for trading securities in OTC markets explicitly provide the option to delay settlement. ${ }^{11}$ Since the flexibility around settlement arises from private decisions, this suggests that lenient treatment of fails eases the expansion of dealer networks and the emergence of market designs that allow for delayed settlement promotes market liquidity. One theoretical question that emerges is under what conditions the intermediation benefits of dealer networks balance the burden of counterparty risk.

Another related active field focuses on the architecture of inter-bank networks. For instance, Elliott, Golub, and Jackson (2014) study cascades of failures in a network of interdependent financial institutions where network diversification and integration face trade-offs with the risk of contagion. Cabrales, Gottardi, and Vega-Redondo (2017) investigate the socially optimal design of financial networks and the trade-off between risk sharing and contagion. Farboodi (2014) and Hugonnier, Lester, and Weill (2018) study how bilateral

\footnotetext{
${ }^{9}$ The rich literature on financial networks also includes important papers looking at network formation in OTC markets. Glode and Opp (2016) show that longer paths of intermediaries may be needed to sustain efficient trade because of information asymmetries. Sambalaibat (2018) build a search-based model of network formation where a core-periphery network arises from specialization. Colliard and Demange (2017) derive equilibrium prices, volumes, and the number of intermediaries in a model with successive take-it-or-leave-it offers.

${ }^{10}$ One way to check that reputation costs are very low is by noting that the price paid to borrow a bond and satisfy settlement obligation does not rise beyond the direct costs of a settlement fail. Empirically, this is the case in our sample (see Berger-Soucy et al. 2019).

${ }^{11}$ The contract also provides a buy-in procedure to terminate the trade. This mechanism is costly and rarely used in the bond market (if ever), but this threat means the contract is not open-ended.
} 
exposures and the core-periphery network emerge endogenously. In contrast with rare default events, the "contagion" of settlement fails is common, and we observe a wide variety of networks in the cross-section of bonds or over time. This should offer a useful ground to compare models.

Section 1 provides the details about our data from the market for Government of Canada bonds. Section 2 documents how dealer networks change around the release of economic data. Section 3 covers settlement fails and documents larger clusters of fails around new. Section 4 documents the relationship between fails and dealer-network complexity across the sample, confirms the centrality premium in our sample and explores the impact of netting by the CCP. Section 5 concludes.

\section{Network Data}

We merge several sources, including proprietary and regulatory data, to construct a rich panel dataset that describes trading activity for Government of Canada bonds for the years 2016 and 2017. We restrict the sample to bonds denominated in Canadian dollars and we ignore inflation-linked bonds and Treasury bills, resulting in a sample of 67 Government of Canada coupon bonds. Our dateset includes information about trades and counterparties, for both the spot bond market and the repo market. To thoroughly observe the network of settlements, it is essential to cover both markets because of the prevalence of short-selling in the market for government bonds. A large share of trading volume and settlement fails involves bonds that are borrowed in the repo market to cover short sales. For reference, Table 2 provides the short names, descriptions and sources of every key variable. Data on and variables for settlement fails are introduced in section 3. 


\subsection{Bond Data}

We first compute basic market variables for each bond and for each day. We compute the repo spread, defined as the difference between the Bank of Canada's target overnight interest rate and the repo rate. The repo spread is a measure of bond scarcity; it measures how costly it is to borrow the bond. We also compute a proxy for the velocity of a bond in the securities-lending market. Our velocity proxy is the ratio of the par value being loaned to the quantity of bonds outstanding (i.e., the float). ${ }^{12}$ Finally, we compute the daily average bid-ask spread on the Candeal dealer-to-client trading platform, which we use as a proxy for a bond's liquidity.

Table 3, Panel (A) reports summary statistics of these bond-level metrics for benchmark bonds and non-benchmark bonds, respectively. A Government of Canada bond achieves benchmark status when its amount outstanding reaches a desired level. Benchmark bonds are more liquid than other bonds, analogous to on-the-run treasuries in the United States. ${ }^{13}$ Benchmark bonds have smaller bid-ask spreads, are more expensive to borrow on the repo market and have higher velocities, relative to non-benchmark bonds.

\subsection{Network Data}

We reconstruct the dealer network for each day and each bond, using trade-by-trade data. Dealers in the Government of Canada bond market report spot and repo market trades to the Market Trade Reporting System (MTRS). This dataset includes details of the trades as well as counterparty identities.

\footnotetext{
${ }^{12}$ The velocity label is appropriate because of the analogy to fractional-reserve banking. The number of settlement claims on a specific bond may expand beyond the stock of bonds of the same issue. In the analogy, the quantity outstanding for this bond represents base currency and settlement claims represent demand deposits. Changes in velocity make the bond supply elastic.

${ }^{13}$ Government of Canada bonds do not become benchmark until a few months after issuance, with the number of months known and varying across maturities. The age of a benchmark bond is around 9 months, on average. See Bulusu and Gungor (2017) for more information about the life-cycle of Government of Canada bonds.
} 


\section{Figure 1: Dealer Settlement Network}

One settlement network in spot and repo markets, extracted from the data for one bond and one day. This network has 26 counterparties, 31 links and 259 distinct paths. The longest path has 7 links. Data are for the Government of Canada bond market for the years 2016 and 2017.

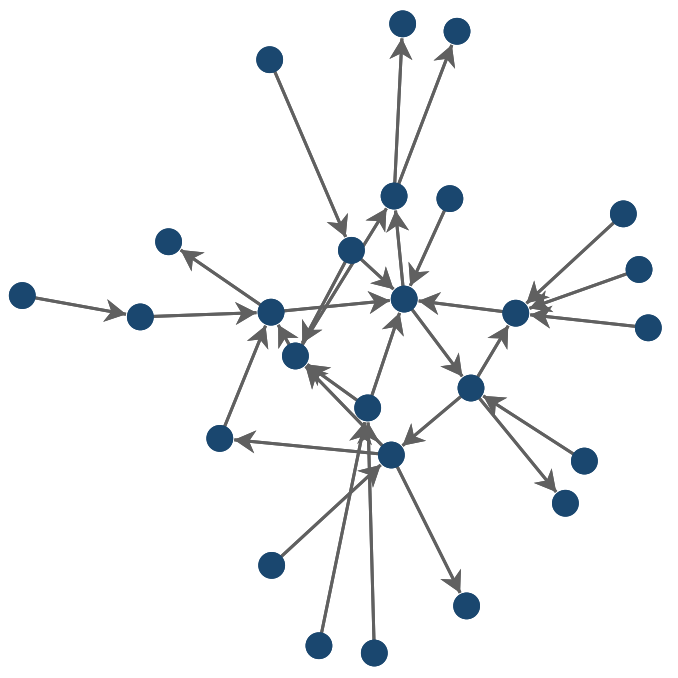


To construct the network for a given bond and a given day, we first assign one node to each dealer and to each client. We draw a link between every pair of nodes where the net settlement volume of this bond on this day is not zero. Links are directed based on which counterparty owes securities (as opposed to cash). Bonds with no trade on a given day are treated as missing values. For some client trades, the unique counterparty identifier is not available. When this happens, we create, for each dealer, one node that groups all of its clients for which we are missing a unique identifier. When a trade is centrally cleared, we draw a link from the dealer to the CCP. This construction produces more than 17,000 bondday networks, with each observation describing one core-periphery network of transactions. Figure 1 shows the network for one bond for one day at the end of 2017. This network had 18 nodes and 20 links on that day, which is in line with the fact that bond-market activity in Canada is concentrated among large dealers and institutional investors.

For each network (one for each day and each bond), we compute NeTwork Volume as the sum of the net settlement volume across all links, which measures the volume of transactions that are expected to settle on a given day, for a given bond. This is the volume of settlements that could potentially fail. NETwork Volume is also a measure of the quantity of intermediation provided by dealers.

Finally, we construct several standard network metrics that summarize the key properties of a network. We define a directed path between two nodes as a sequence of links connecting the nodes for which the flow of securities between the nodes goes in one direction. To illustrate, a path with two links has counterparty A delivering bonds to counterparty B, who is then delivering bonds to counterparty C. With this definition in hand, we compute the number of distinct paths (PATHS), the average path length (AvGPATH), the length of the longest path (DiAmETER) as well as the network density (DENSITy). ${ }^{14}$

\footnotetext{
${ }^{14}$ Note that we do not identify sequences of trades by using time stamps arranged as a continuous sequence. This identification strategy has been used by Green, Hollifield, and Schürhoff (2007); Li and Schürhoff (2019). It performs well for bonds that trade infrequently, like municipal bonds. However, dealers in the government
} 
Table 3, Panel (B) reports the summary statistics for the network data separately for benchmark and non-benchmark bonds. One important observation is the large diversity of network structures. Focusing on the inter-quartile range, the number of Links ranges between 8 and 29 for non-benchmark bonds and between 83 and 107 for benchmark bonds. The number of PATHS also shows large variations. Since these metrics are highly correlated with each other, we summarize them with their first principal component, which we call Complexity. Figure 2 shows the time series of Complexity for the 10-year benchmark bond and for a bond that was originally issued with 10 years to maturity but that is not a benchmark bond in our sample. The COMPLEXITY is much higher for the benchmark bond, which means that dealer networks tend to be bigger and more complex for bonds that are more liquid.

\section{Dealer Networks and News}

The arrival of public information in the bond market sets off episodes where prices adjust quickly and trading volume surges for a prolonged period (Ederington and Lee, 1993; Fleming and Remolona, 1999). Given the central role played by dealer networks, we ask whether they adjust to the release of new public information. We collect information about the following Canadian data releases: inflation, unemployment, retail sales, GDP and monetary policy announcements, which are the most significant news releases. The timing for each release follows a pre-announced schedule; and bond investors closely follow each release.

Panel (A) of Figure 3 shows the average change in COMPLEXITY around news releases. ${ }^{15}$ We distinguish between the response in dealer networks for benchmark bonds and for non-

bond market can sell bonds with the expectation of finding an offsetting spot trade at a later time during the day. A dealer may also choose to sell bonds today, but look to borrow these bonds in the repo market on the day of settlement. The settlement day was either $t+3$ or $t+2$ early in the sample but changed on September 2017 to $t+2$ only for all maturities. In any case, the path between the buyer and the ultimate seller cannot be identified with trade time stamps. Given the option to wait, dealers can use offsetting positions in other bonds to hedge or mitigate interest rate risk.

${ }^{15}$ We drop any overlapping news events, specifically, where news releases occur within four business days of each other. This produces 78 distinct news release events in our sample. 
Figure 2: Time Series of CoMPlEXITY

Weekly average COMPLEXITY for the 10-year benchmark bond, which tracks different bonds because the benchmark status changes over time, and an old bond with 6 years to maturity at the beginning of the sample. Complexity is the first principal component of the network metrics in Table 3. Data are for the Government of Canada bond market for the years 2016 and 2017. Table 2 provides all variable definitions.

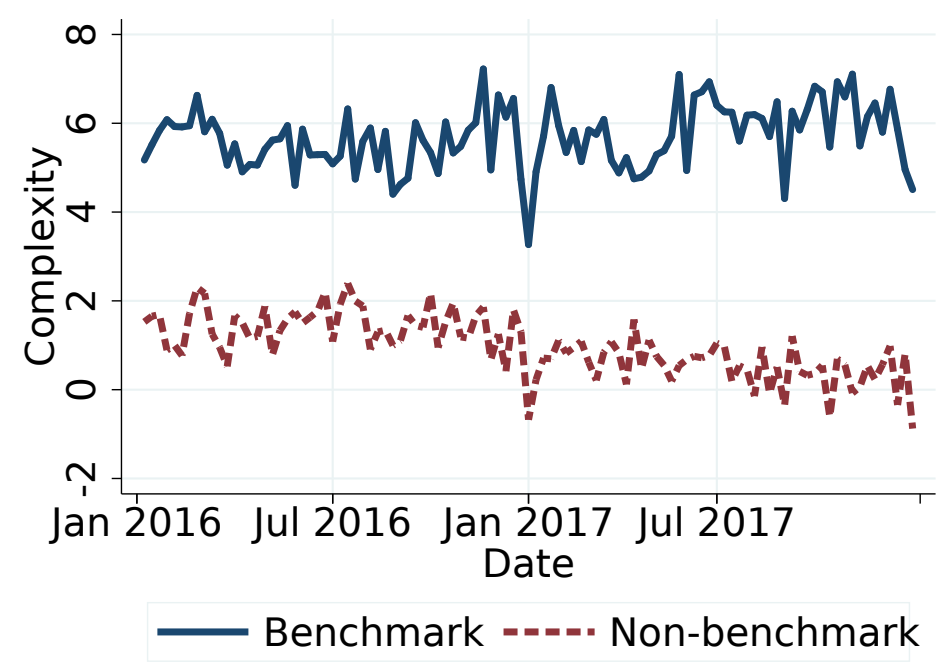

benchmark bonds. Trading activity following the news releases is likely to be concentrated around the most liquid bonds, where trading is cheaper. We find that Complexity increases significantly for benchmark bonds, by 0.4 standard deviations $^{16}$ on the day of the news and the increase persists to the next day. By contrast, Complexity increases by 0.1 standard deviation for non-benchmark bonds. Figure 3 also shows changes in dealer networks where the sample is divided into high- and low-COMPLEXITy bonds, using the median values of Complexity two days before each news release. The results are similar, but the magnitudes are smaller, since the benchmark bonds have the highest complexity.

One reason the COMPLEXITY of dealer networks increases around news releases is to accommodate the higher demand for intermediation. To check this we calculate the change in Network Volume around news events. Panel (B) of Figure 3 shows that Network VOLUME increases on average for benchmark bonds. The impact of news releases is signif-

\footnotetext{
${ }^{16}$ The standard deviation of COMPLEXITY is normalized to one.
} 


\section{Figure 3: Dealer Networks and News}

Sample averages of changes in Complexity and NeTwork Volume in the days around economic news releases, separately for benchmark and non-benchmark bonds. For each bond and for each event, we compute the change in COMPLEXITY and NeTwork Volume as the difference between their values after the release and their values on the day before. Time is normalized so that 0 is the day of a news release, -1 is the day before and 1 is the day after. A 90 percent confidence interval is shown by the vertical lines. By construction, variables and confidence intervals are zero at time -1. Data are for the Government of Canada bond market for the years 2016 and 2017. Table 2 provides all variable definitions.

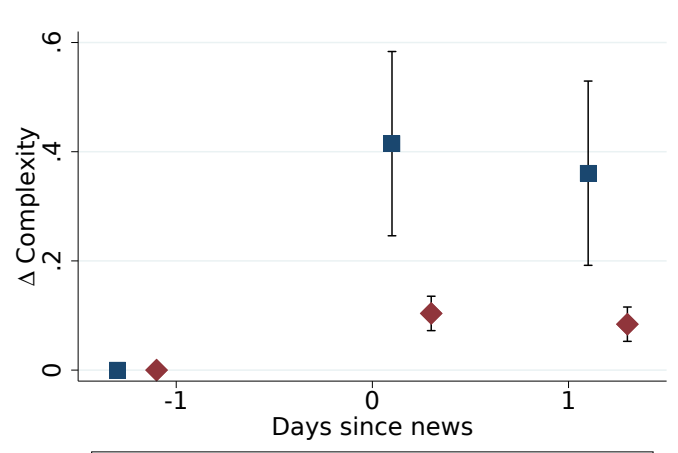

Benchmark Bonds Non-Benchmark Bond\$

(A) Complexity-I

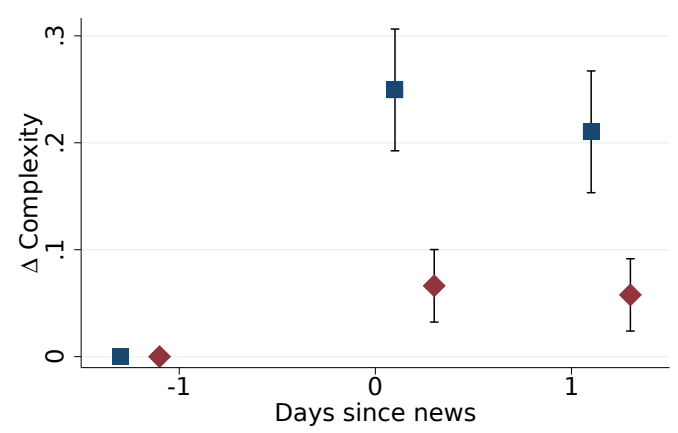

High Complexity Low Complexity

(C) Complexity-II

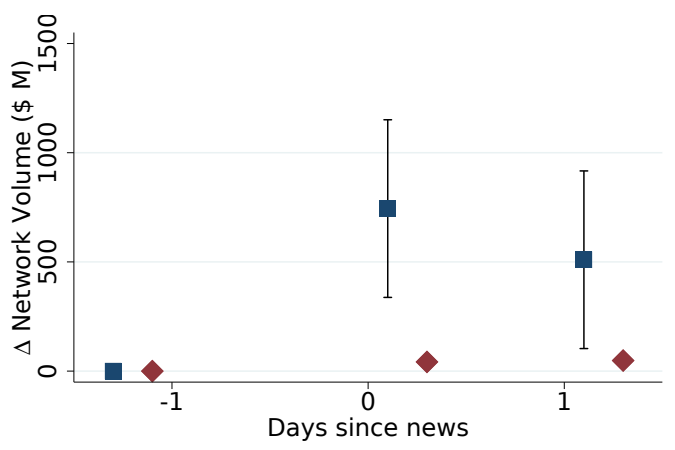

Benchmark Bonds Non-Benchmark Bond\$

(B) Network Volume-I

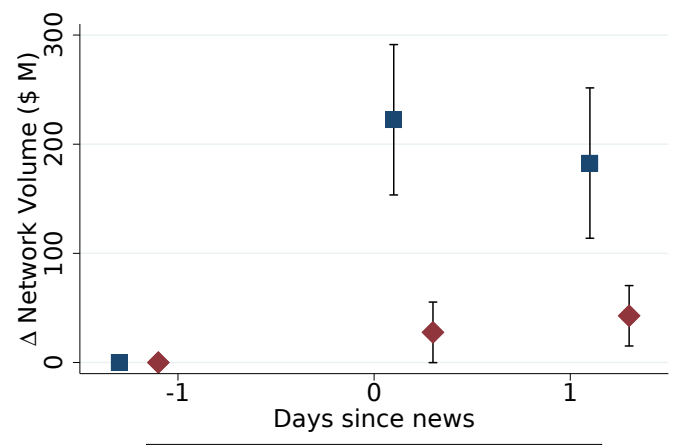

High Complexity Low Complexity

(D) Network Volume-II 
icant: Network Volume increases by $\$ 750 \mathrm{M}$, on average, which is around 0.25 standard deviations. By contrast, the impact is very small for non-benchmark bonds.

Panels (C)-(D) of Figure 3 show the results from the same exercise, but to split the sample we used the median of the network Complexity two days before the news. We expect similar but somewhat muted results because benchmark bonds have the most complex network. We find that Complexity increases by 0.25 standard deviations and Network Volume increases by $\$ 225 \mathrm{M}$ for dealer networks in the high-CoMPLEXITY category.

To summarize, Figure 3 shows that dealer networks change significantly around news releases. These changes are concentrated in networks for bonds that are already very active, which is precisely where investors can expect to find immediacy as they change their portfolios' exposure to interest rate risk. Since the news releases are exogenous, the evidence can be interpreted as causal. We find that NETwORK Volume increases, which means that, at settlement time, the volume of bonds that flow through the networks increases after news releases. This is consistent with higher profits for dealers (we checked that both the B/A Spread and the Spot Mark-Up increase on these news days). In addition, the Complexity of dealer networks also increases significantly after the news releases. The increase in Complexity can be due to an increase in bilateral trades, the creation of longer chains of trades between ultimate buyers and sellers, or a combination of these. Overall, this provides strong evidence that dealer networks adapt to and accommodate a higher demand for intermediation. 


\section{$3 \quad$ News and Settlement Fails}

This section documents that dealer networks are more likely to experience large clusters of settlement fails after news events, especially for bonds in dealer networks with higher complexity. We also establish three important stylized facts that help make the connection between settlement fails and dealer networks. First, fails in repo and spot markets are closely related, which is consistent with a trading network that covers both markets. Second, fails exhibit very fat tails, which is consistent with the idea that fails cascade through the trading network. Finally, fails exhibit persistence and can run for several days, which suggests that fails are often widespread across the network.

\subsection{Settlement Fails Data}

For each bond and each day, we compute the total volume of transactions that is expected to settle and the volume that fails. In most of the results below, we group repo and spot market fails together. The appendix provides more details about the computation and Panel (C) in Table 3 reports the summary statistics.

Figure 4 reports fails as a share of the total volume for specific bonds, separately for the repo and spot markets. Data are for Government of Canada bonds market for the Q4 2015 until Q4 2017. Panel (A) shows these shares for the 10-year benchmark bond and Panel (B) shows these shares for a non-benchmark bond with 6 years to maturity at the start of our sample. The failed volume often ranges between 5 and 10 percent of the total volume for the benchmark bond and between 5 and 20 percent for the non-benchmark bond. Table 2 provides all variable definitions.

One key observation in Panel (C) of Table 3 and in Figure 4 is that the distribution

of fails is highly asymmetric, with many observations close to or at zero and a fat tail of large fails. This pattern corresponds to the description in Fleming and Garbade (2005) of "daisy chains" as fails cascade through the settlement network, creating this fat tail of large 


\section{Figure 4: Time Series of Repo and Spot Fails}

Weekly average of FAILS as a percentage of settlement volume for all spot and repo market trades for the 10-year benchmark bond in Panel (A) and for a bond that was once a 10-year benchmark in Panel (B). This non-benchmark bond which had 6 years to maturity at the beginning of the sample. Data are for the Government of Canada bond market for Q4 2014 to Q4 2017.

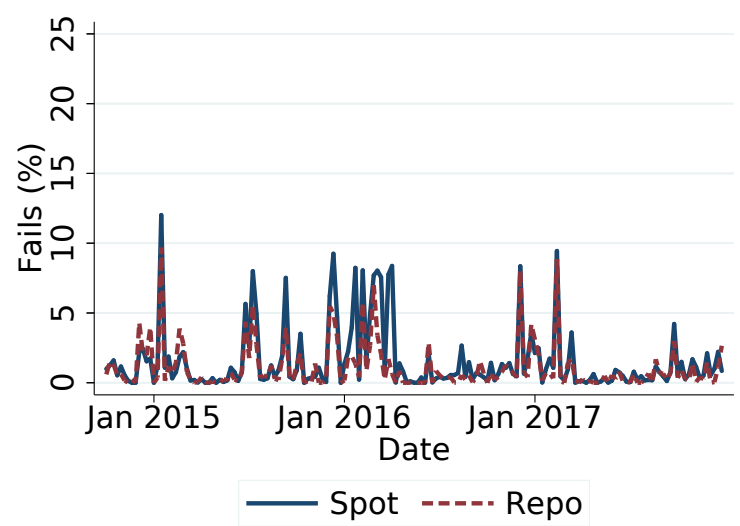

(A) Benchmark Bond

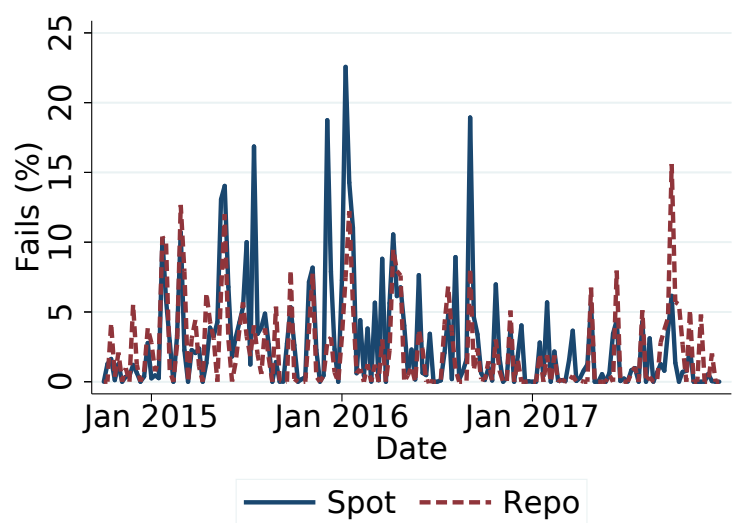

(B) Non-Benchmark Bond

settlement fails. One interpretation of these cascades is that whether one trade will fail is correlated with the outcomes for other trades. This is a very important stylized fact that connects fails with the presence of a dealer network.

To see the importance of the correlation between fails, we can use simulation in the population of trades. The first simulation assumes that fails are not correlated. The second simulation assumes a fixed pairwise correlation, which corresponds to the idea of a cascade. ${ }^{17}$

Table 4 reports summary statistics for the observed and simulated distributions: the number of bond-days with zero fails (the left tail), the mean and variance of fails volume, as well as the 95th and 99th quantiles (the right tail). The key message is that allowing

\footnotetext{
${ }^{17}$ We implement both simulations for spot trades $(1,189,012$ observations in our sample). The first simulation assumes that any given trade will fail with a fixed probability $p$ and that any trade fails independently of other trades. The parameter $p$ is calibrated to match the average percentage of failed trades, which is 0.54 percent. The simulation yields a binomial distribution of fails $B(n, p)$ for each bond-day where $n$ is the number of trades. The second simulation uses the same probability $p$ that any given trade will fail but also assumes a fixed pair-wise fail correlation $\rho$ between trades. By design, this generates a beta-binomial distribution with parameters $n, p$ and $\rho$, nesting the binomial case when $\rho=0$. The correlation parameter $\rho$ is calibrated to match the unconditional variance of the fraction of failed trades $(\rho=0.037)$. We sample in each bond-day, using these assumptions. We can sample from the beta-binomial, using standard algorithms.
} 
for correlation closely matches the observed distribution in both the number of bond-day observations with zero fails and in the right tails with very large fractions of failed trades. By contrast, simulating without correlation generates the wrong distribution. The dispersion is too small and the observations with zero fails or with large fails are both too infrequent. This is robust evidence that correlation is a key stylized fact of fails. One mechanism for this correlation is that fails propagate through settlement networks.

Another observation that connects fails with the presence of dealer networks is that they are closely related across the repo and spot markets. Panel (C) of Table 3 shows that the volume of fails is evenly split between repo and spot market trades. This is because not all counterparties in a settlement network hold the bond in their inventory but instead borrow the bond with a repo trade. Selling securities short is essential (selling securities that dealers do not hold), and settlement fails are not simply a side effect but a key feature of these markets. If fails were treated as a contractual default, then dealers could only sell securities that they held.

\section{Figure 5: Run Length of FAILS}

Histogram of run length of FAILS in our sample. A run is defined as the length of any continuous sequence of days where a given bond has FAILS greater than zero. The histogram shows the fraction of bond-days with a given length. Data are for the Government of Canada bond market for the years 2016 and 2017.

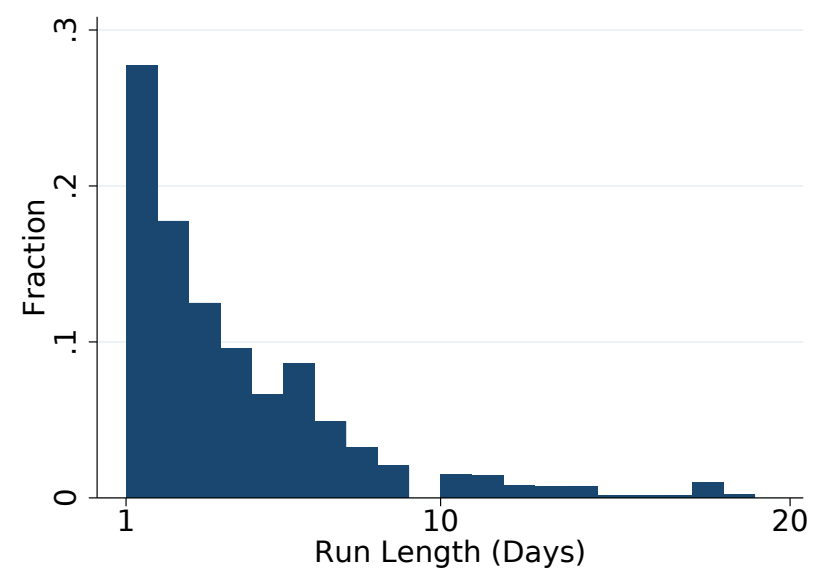


Another important stylized fact is that fails tend to persist over time. Once a cascade occurs for a given bond-day, it can takes a few days for the failed volume to return to zero. One simple way to see this is to measure, for any given bond, the length of runs of continuous days with positive fails. Figure 5 shows the histogram of all run lengths in our sample. The majority of observations run for more than one day, but essentially all observations show a length of 10 or fewer days. ${ }^{18}$

\subsection{Settlement Fails and News}

Figure 4 shows that fails exhibit clusters with large fail volumes. These spikes often correspond to the release of new economic data. Table 1 lists the share of the volume that failed in the week of the largest unemployment, retail sales, GDP and CPI news releases, respectively, as well as the largest surprise interest-rate changes by the Bank of Canada. This confirms that several of the spikes in Figure 4 occurred around economic news.

\footnotetext{
${ }^{18} \mathrm{~A}$ standard test of serial independence based on runs yields a p-value of essentially zero (unreported).
} 
Table 1: Episodes of Fails after Large News Surprises

The table shows the date of the largest surprises for each of our economic news variables, as measured by the deviation from the median analyst forecast. The table also lists the fails as a percentage of the volume for the 10-year benchmark bond during the week of the news release.

\begin{tabular}{ccc}
\hline Week Starting & Fails Per Volume (\%) & Event \\
\hline 19 Jan 2015 & 4.1 & Interest rate cut \\
31 Aug 2015 & 1.3 & Unemployment above forecast \\
18 Jan 2016 & 3.0 & Retail Sales above forecast \\
29 Feb 2016 & 7.4 & GDP above forecast \\
13 Feb 2017 & 5.1 & CPI above forecast \\
\hline
\end{tabular}

Heuristically, the reason news might cause settlement fails or changes in the dealer network is that the network is not static. This is what Figure 3 shows. Bond investors may choose to change their portfolios after the release of new economic information. For instance, some investors may sell some of their bonds and, to execute this sale, they must recall any of the bonds they had lent. This forces their counterparts to search for bonds that are available for lending, leading to new settlement links in the network and, possibly, to fails.

Panel 5A reports the quantiles of the changes in fails around news releases: the 50th, 75th, 90th, 95th and 99th percentiles. Again, we separately report the impact for benchmark bonds and non-benchmark bonds. We find a shift in the distribution of fails: its asymmetry and the size of the tails increase substantially. The increase in fails is $\$ 400 \mathrm{M}$ and $\$ 2,000 \mathrm{M}$ at the 95th and 99th percentile for benchmark bonds, respectively, which corresponds to increases of 1 and 5 standard deviations. The impact for non-benchmark bonds is only $\$ 50 \mathrm{M}$ and $\$ 260 \mathrm{M}$, which corresponds to increases of 0.5 an 2.5 standard deviations. Note that, by contrast, the median increase is zero for these bonds. Hence, looking only at the mean could result in missing an increase in the size of the relatively infrequent but very large cluster of fails.

Panel 5B reports results for the same exercise but this time splitting the sample between dealer networks with low and high ComplexiTy. The sub-sample with high CompleXiTy 
includes benchmark bonds (see, e.g., Figure 2), but it also includes other bonds with more active dealer networks relative to those of other bonds. The results are qualitatively similar. The 95th and 99th percentiles increase by $\$ 170 \mathrm{M}$ and $\$ 530 \mathrm{M}$, respectively, for bonds with high Complexity. The reason the effect is smaller than when we split the sample using the benchmark status is that the latter category includes bonds with the highest COMPLEXITY. Overall, Table 5 shows that the impact of news on fails increases with trading activity, proxied by the benchmark status, and with the level of dealer network COMPLEXITY.

We also estimate the increase in fails around news releases in the context of quantile regressions, where we control for several important variables. Because CompleXITY is correlated with trading activity (e.g., settlement volume) and scarcity (e.g., repo spread), we want to know whether the interaction between news events and COMPLEXITY is subsumed by other variables. Table 6 presents the results of the quantile regression targeting the 95th percentile. Below, we present additional results for other percentiles. The dummy variable AfTER has a value of 1 on the day of the news and the two following days, since spot market transactions occurring on the day of the news can settle over the next two days. Its coefficient is always positive and significant. In the baseline regression (Column 1), coefficients of the control variables have the expected signs, indicating that bonds with higher volume, scarcer bonds and bonds that are more liquid exhibit more fails.

Next, we add either a Benchmark dummy or the dealer networks' Complexity to the baseline (Columns 2 and 3, respectively). Consistent with the results in Panel 5A, both coefficient estimates are significant and positive. Finally, we augment the baseline with both of these variables (Column 4). The coefficient estimate for Complexity is essentially unchanged and remains highly significant. By contrast, the coefficient estimates for Benchmark and Network Volume are much smaller and become insignificant.

The results provide strong evidence that the increase in fails around news releases is much higher for dealer networks that are more complex, even after accounting for the possible me- 
chanical increase due to a higher volume or to higher velocity. The evidence also suggests that the Complexity of dealer networks subsumes both Network Volume and Velocity. We argue that the dealer network is the mechanism that connects the news to the increase in large fails. One the one hand, complexity is a plausible mechanism because dealer networks can magnify localized fails into a cascade. On the other hand, dealer networks become more complex around news releases because they accomodate the higher demand for intermediation. Hence, the evidence unveils an important trade-off between trading immediacy and the counterparty risk associated with settlement fails when the complexity of dealer networks increases.

\section{Settlement Fails in Dealer Networks}

\subsection{Fails and Dealer Networks}

Sections 2 and 3 use exogenous variation from the release of new economic data. New information about the economy causes dealer networks to expand their intermediation services, but this expansion is associated with an increase in fails. In the following, we show the strength of the relationship between the state of the dealer network and the volume of settlement fails, using all bond-day observations (instead of focusing on observations around news releases). To be clear, this is not causal evidence, but the results are useful to understand the relevance of dealer networks to the propagation of fails.

We first estimate a logit model for the occurrence of some $(>0)$ fails for each bondday, given the network variables and other controls. This stage measures the relationship between the state of the dealer network and the likelihood of some fails. We then estimate a linear model by ordinary least squares for the volume of settlement fails, conditional on the occurrence of some fails. This stage measures the relationship between the dealer network and the size of the fail, given that there are some fails. We use two stages because the distribution of fails has two modes, including a large mass at zero. 


\section{Likelihood of Fails}

Table 7 reports the results for the first stage. We find that the likelihood of FAILS increases with the number of Links, Paths, the Avgpath and the Diameter. The effect is statistically significant even after controlling for market activity, bond scarcity, liquidity and bond characteristics. The signs of the estimated control coefficients are as expected; settlement fails are more likely for bonds that are more active, scarce and liquid. However, the coefficient estimates for Network Volume and Benchmark become insignificant when Complexity is also present in the regression. This is consistent with the previous results in Column 4 of Table 6: the complexity of the network is a more important determinant of fails than the trading volume or benchmark status.

Figure 6, Panel A illustrates the partial effect of network metrics on the likelihood of fails implied by the estimated Logit regression. We report estimated probability of fails, varying values of each metric between their first and last sample deciles, when holding all other variables to their median values. We repeat the exercise for Complexity, Links, Paths, Avgpath and Diameter. We find that Complexity has the largest impact on the predicted probability. Increasing the value of COMPLEXITY from its lowest to its highest decile raises the probability of fails from 20 percent to above 40 percent. Corradin and Maddaloni (2019) find that 1-basis-point change in the repo spread increases the probability of some fails by 0.32 percent. We find a similar but slightly stronger result: 1 basis point increases the probability by 0.8 percent. One reason we find a higher estimate is that our results are for Canada, while Corradin and Maddaloni (2019) study the bond market in Italy. Another reason is that we include data for both spot and repo trades.

Figure 6, Panel B shows the likelihood of fails as DiAmETER varies over its sample deciles,

as in Panel A, but includes the counterfactual case corresponding to a fully centrally cleared market. In this case, all trades are conducted through the CCP and the diameter of the network is 2. The difference between the observed case and the counterfactual case is large 
when the diameter is large - in the last sample decile, the estimates suggest large benefits of central clearing networks, trades are 10 percent less likely to fail.

\section{Figure 6: Dealer Networks and the Likelihood of Fails}

Partial effects of varying individual network metrics on the likelihood of fails, estimated with a logit regression. Each network metric varies between the first and last sample decile values, keeping all other variables at their respective sample median values. Data are for the Government of Canada bond market for the years 2016 and 2017. Table 2 provides all variable definitions.

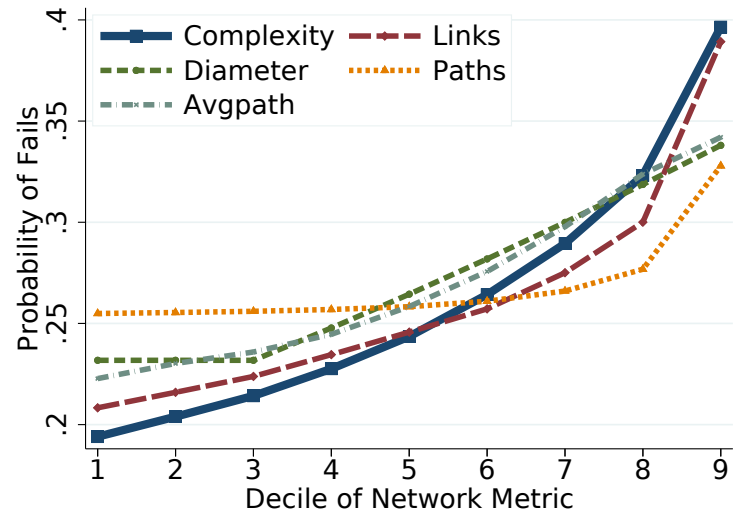

(A) Marginal Effects

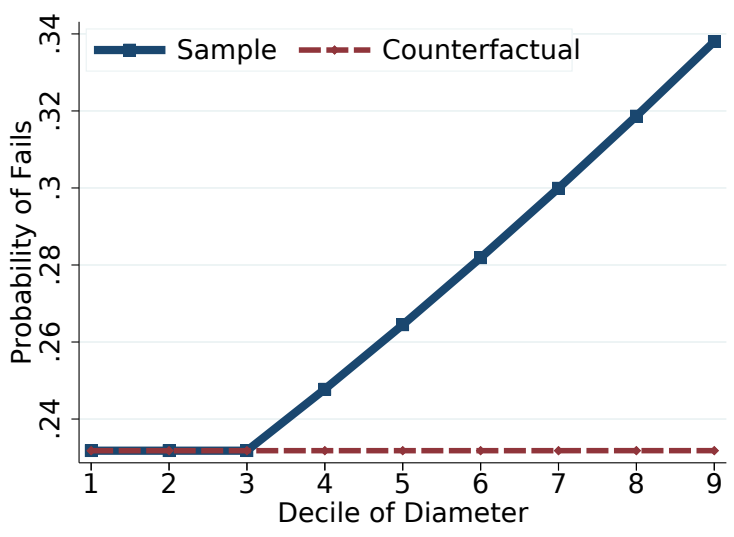

(B) Counterfactual - Full Central Clearing

\section{Volume of Fails}

Table 8 reports the results from the second stage. We find evidence that the size and complexity of dealer networks also affect the volume of fails, conditional on some fails. Increasing COMPLEXITy from its first to last decile increases the expected volume of fails from around $\$ 11 \mathrm{M}$ per bond to above $\$ 34 \mathrm{M}$ (at the mean of the distribution). The results are significant and robust. As expected, we also find that scarcity, trading volume and velocity predict a larger volume of fails volume, with significant estimates. Interestingly, the coefficient for the BENCHMARK dummy variable is not significant when COMPLEXITY is present in the regression.

Taken together with the results from the logit regression, the partial effect of increasing Complexity from its first to last decile increases the average volume of fails from around 
$\$ 2 \mathrm{M}$ to $\$ 14 \mathrm{M}$ per bond per day. ${ }^{19}$ However, this is the partial effect at the mean of the FAILS distribution. We expect the Complexity to be related to the expected size of large fails because of the potential for cascades. Table 9 reports the coefficient estimates for Complexity from quantile regressions for the 75th, 90th, 95th and 99th percentiles. The regressions are otherwise identical to the specification in the fourth column of Tables 7-8. Figure 7 illustrates the estimated partial effect of COMPLEXITY on each of these percentiles. As expected, the shift in the larger percentiles is much greater: the 95th percentile increases by $\$ 120 \mathrm{M}$ between observations with low or high COMPLEXITY.

\section{Figure 7: Dealer Networks and the Volume of Fails}

Partial effects of varying individual network metrics on the size of fails estimated with OLS. Each network metric varies between the first and last decile values, keeping all other variables at their respective sample medians. Data are for the Government of Canada bond market for the years 2016 and 2017. Table 2 provides all variable definitions.

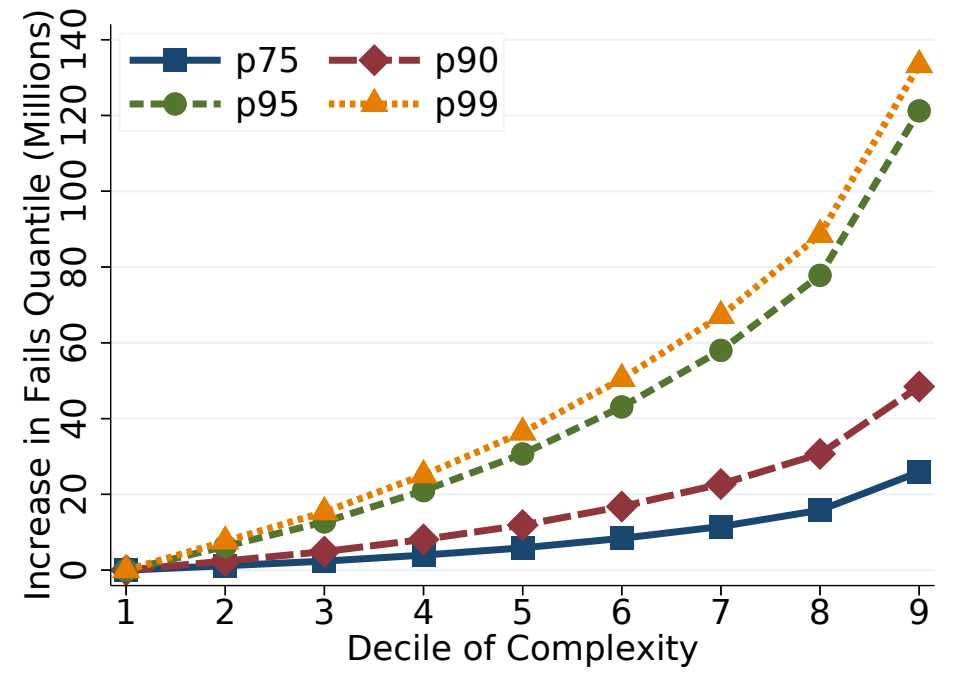

\subsection{Centrality}

Li and Schürhoff (2019) show that more dealers with a central position in the network earn

\footnotetext{
${ }^{19}$ Corradin and Maddaloni (2019) find that an increase in the repo spread of 1 basis point increases the share of the trading volume that fails by 0.05 percent. Repeating the regression in our sample but substituting the share of trading volume that fails as a dependent variable, we find that the effect of 1 basis point is 0.09 percent.
} 
a profit when providing immediacy to peripheral clients. We document similar results in our sample. We are interested in the trade-off between the costs due to fails and the benefits of dealers' intermediation services. Hence, we ask whether the size and complexity of the dealer network also play a role in the provision of intermediation. Further, are the dealers' profits higher when the network is larger and the clients are more remote?

One common feature across this variety of networks is that the share of links in the network relative to the number of all potential links is typically very close to zero (unreported), which tells us that many nodes are not connected to each other. This can happen in a core-periphery network that is intermediated by a few central dealers. Following Li and Schürhoff (2019), we compute several metrics to capture the centrality of dealers and clients: In-Degree, Out-degree, Eig-Centrality, Betweenness, Closeness Clustering; we then use their first principal component CENTRALITY in the following.

Next, we check whether clients who are more remote in the periphery pay a higher price to trade via the dealers' network. For spot and repo trades, we compute the average Spot MARK-UP (REPo MARK-UP) between dealers and clients. For each transaction between a dealer and a client, and for each bond and each day, we compute the difference between the transaction price (repo rate) and the average price (repo rate), in absolute value. SPOT MARK-UP and REPo MARK-UP are measures of half-spread, so we multiply by two for a comparison to the bid-ask spreads. We then average across all dealer-client transactions. Given these measures, we ask if the mark-up increases when the client's centrality is lower.

Table 10 reports the results from regressions of the mark-ups on the centrality measures in each market. The control variables include the network COMPLEXITY and other variables as in Table 8. The results are similar in the spot and repo market. Clients tend to pay a higher mark-up if they are less central in a network of transactions or if they transact with a dealer that is more central in the network. We find similar results if we use in the regression the difference between the dealers' and the clients' centrality. The control coefficient estimates 
(unreported) show that the mark-up is lower for benchmark bonds or bonds that are more liquid, but the markup is higher for bonds that are more expensive to borrow (unreported).

The results are economically significant. Incrementing $\triangle$ CENTRALITY from its first to its last sample decile corresponds to a change of around 4 cents in SPOT MARK-UP and around 3 basis points in REPO MARK-UP. The magnitude of the change in SPOT MARK-UP is similar to the average bid-ask spread (see Table 3). These results are similar to those in Li and Schürhoff (2019) who find that central dealers charge a centrality premium that is around the same size as the bid-ask spread.

These results point to an important explanation for the emergence of market designs that allow for settlement fails with a relatively benign penalty. Without this design feature, it could be too risky or too costly for dealers who are involved in long or complex networks to provide liquidity. The results also show a trade-off between trading immediacy and the counterparty risk associated with settlement fails. We leave these questions for future research.

\subsection{Central Counterparty}

Our central result is that the size and complexity of the dealer network is an important mechanism in the propagation of settlement fails. One natural way to simplify the network of transactions is to net these transactions via a central counterparty (CCP). Bond dealers in Canada have the option, but no obligation, to send their spot and repo trades to a CCP. ${ }^{20}$ In our sample, every member of the CCP is a dealer. By providing multilateral netting, the CCP may reduce the complexity of the network and, in the extreme case where the CCP novates all trades, the number of links and paths in the network would be the same as the number of counterparties. In this case, the diameter of the network is two links. If the CCP's coverage of the market is partial, then this may also increase the complexity of the network.

\footnotetext{
${ }^{20}$ See Deloitte (2018) for details about the evolution of the CCP for repo and spot transactions in Canada.
} 
The benefits from multilateral netting decline rapidly if the CCP only clears a fraction of trades. The intuition is similar to the analysis of Duffie and Zhu (2011).

In the following, we check the role of the CCP by reconstructing the counterfactual networks without a CCP. We limit our analysis to inter-dealer trades because dealers were the only participants with access to the CCP in our sample period. We also limit our analysis to only over-the-counter trades, since trades done on trading platforms are often anonymous, which means that we do not observe the pair of trading counterparties before the novation by the CCP.

Table 12 reports the summary statistics in the sub-samples where the CCP handles different shares of the inter-dealer trades. For most of bond-day observations $(N \sim 23,000)$, the CCP handles less than 25 percent of all trades. However, there is a substantial dispersion in the share of trades the CCP handles. There are several thousand observations for which the CCP handles more than 25 percent, more than 50 percent or more than 75 percent of overall trades. Looking at the summary statistics in each bucket, we find only small differences in Volume, Repo Spread, Velocity, B/A Spread, Age and Float.

Table 12 reports the summary statistics of the inter-dealer network metrics. The left column reports the sample statistics and the right column reports counterfactual statistics where the links to the CCP are replaced with the original counterparties to a trade. The results show small but positive differences between the actual data and the counterfactual data, showing that, if anything, the CCP makes the network slightly longer and more complex. For instance, disconnecting the CCP decreases the number of links from 5.3 to 4.5 , the number of paths from 11 to 8 and the principal network component CoMPLEXITY from 0.27 to -0.27 . The main reason for these counterintuitive results is that the CCP handles a small share of trades, on average. In addition, where the CCP has larger coverage, networks tend to be smaller and the multilateral netting benefits also tend to be small.

Confirming the intuition of Duffie and Zhu (2011), one message is that benefits from 
multilateral netting decline rapidly if the CCP only clears a fraction of overall trades. This is the case for most of our sample and it is likely to be an important impetus to widen CCP access to clients in the network. Another important message is that dealers choose to direct only a small share of their trades to the CCP. This choice reflects the costs and benefits from clearing trades at the CCP (one of the costs is the higher margin requirements and one of the benefits is anonymity). This limits the contribution of the CCP to reducing the complexity of the network and the volume of settlement fails. In particular, in the absence of a coordination mechanism, an individual dealer's decision to direct more trades to the CCP is unlikely to reduce settlement fails.

\section{Conclusion}

We analyze a unique dataset of trades, settlements, fails and counterparties in a large government bond market. Across more than 17,000 dealer settlement networks, we find that larger and more-complex network are associated with larger markups, higher probability of fails and a larger volume of fails. Following news events, we show that as the complexity of dealer networks increases, the intermediation quantity increases, and incidences of large cascades of settlement fails also increase. The evidence suggests that larger dealer networks create trade-offs between intermediation benefits and counterparty risk. It also points to an important explanation for the emergence of market designs that allow a relatively benign penalty for settlement fails. Without this design feature, it could be too risky or too costly

for dealers in large or complex networks to provide liquidity. The government bond market provides a rich data set for future research to study network formation, intermediation benefits and the propagation of counterparty risk. 


\section{A Appendix}

\section{Settlement Data}

We label each trade in the Canadian Deposit for Securities (CDS) data either as a repo or spot trade, and we collect both the traded par value and the planned settlement date. There is one settlement order for each spot trade and two settlement orders for each repo trade. The first order is for the initial exchange of securities for cash, and the second order represents the return of the bond in exchange for the principal and interest. Together, these data represent the "trades" dataset. For each settlement fail, we collect the par value to settle, the planned settlement date and whether it was a spot or a repo trade. This represents the "fails" dataset. For each bond-day, we then combine the trades and the fails datasets to construct the total settlement volume: the sum of both the new and older failed settlement orders. If the settlement fail date occurs after the planned settlement date, then this trade had failed on a prior date and failed again at a new delivery attempt. In this case, we deem the settlement failure an old fail. We exclude observations of settlement fails that are outstanding for more than five days.

For each day in our sample, the settlement volume includes both new trades and the previous day's failed settlements: Total volume $t_{t}=\mathrm{New}$ settlement $_{t}+$ Failed settlement $_{t-1}$. We aggregate all trades by settlement date (and not by trade date) to compute the new settlement volumes for each bond-day. We provide a hypothetical example in the table below. Each record represents a new settlement order generated by a new trade. Note that there are two settlement orders for Trade ID 3 because it is a repo trade. Then bond ABC has 800 new settlement orders for May 3rd and 900 for May 4th.

$\begin{array}{llllll}\text { ISIN } & \text { TradeID } & \text { Trade type } & \text { Trade date } & \text { Settlement date } & \text { Par value } \\ \text { ABC } & 1 & \text { Cash } & \text { May 1 } & \text { May 3 } & 100 \\ \text { ABC } & 2 & \text { Cash } & \text { May 1 } & \text { May 3 } & 200 \\ \text { ABC } & 3 & \text { Repo } & \text { May 3 } & \text { May 3 } & 500 \\ \text { ABC } & 3 & \text { Repo } & \text { May 4 } & \text { May 4 } & 500 \\ \text { ABC } & 4 & \text { Cash } & \text { May 2 } & \text { May 4 } & 400\end{array}$

We then sum all failed settlements for each bond-day, aggregating by fail date. We provide a hypothetical example below. Each record represents a settlement fail. In this example, the repo market settlement failure on May 4 indicates that the counterparty had failed to return bond ABC exchanged as collateral in a repo trade initiated on May 3. The fail volume for bond ABC was 100 for May 3rd and 500 for May 4th.

$\begin{array}{llllll}\text { ISIN } & \text { Trade type } & \text { Trade date } & \text { Settlement date } & \text { Fail Date } & \text { Par value } \\ \text { ABC 1 } & \text { Cash } & \text { May 1 } & \text { May 3 } & \text { May 3 } & 100 \\ \text { ABC 3 } & \text { Repo } & \text { May 4 } & \text { May 4 } & \text { May 4 } & 500\end{array}$

Combining the aggregated trades dataset and the aggregated fails dataset, we have:

$\begin{array}{llllll}\text { ISIN } & \text { Date } & \text { New } & \text { Failed } & \text { Prior days failed } & \text { Total volume } \\ \text { ABC } & \text { May 3 } & 800 & 100 & 0 & 800 \\ \text { ABC } & \text { May 4 } & 900 & 500 & 100 & 1000 \\ \text { ABC } & \text { May 5 } & 0 & 0 & 500 & 500\end{array}$




\section{References}

Allen, F. and D. Gale (1999). Innovations in financial services, relationships, and risk sharing. Management Science 45(9), 1239-1253.

Autore, D. M., T. J. Boulton, and M. V. Braga-Alves (2015). Failures to deliver, short sale constraints, and stock overvaluation. Financial Review 50(2), 143-172.

Babus, A. and T.-W. Hu (2017). Endogenous intermediation in over-the-counter markets. Journal of Financial Economics 125(1), 200-215.

Babus, A. and P. Kondor (2018). Trading and information diffusion in over-the-counter markets. Econometrica 86(5), 1727-1769.

Bátyi, T., C. A. Parlour, and U. Rajan (2016). Relationships in OTC markets. Working paper.

Berger-Soucy, L., J.-S. Fontaine, and A. Walton (2019). Price caps in Canadian bond borrowing markets. Staff analytical note, Bank of Canada.

Boni, L. (2006). Strategic delivery failures in U.S. equity markets. Journal of Financial Markets 9(1), 1-26.

Brancaccio, G., D. Li, and N. Schürhoff (2017). Learning by trading: The case of the U.S. market for municipal bonds. Working paper, Princeton University.

Bulusu, N. and S. Gungor (2017). The life cycle of government of Canada bonds in core funding markets. Bank of Canada Review (Spring), 31-41.

Cabrales, A., P. Gottardi, and F. Vega-Redondo (2017). Risk sharing and contagion in networks. The Review of Financial Studies 30(9), 3086-3127.

Colliard, J.-E. and G. Demange (2017). Cash providers: Asset dissemination over intermediation chains. Discussion Paper No. DP10747, CEPR.

Corradin, S. and A. Maddaloni (2019). The importance of being special: repo markets during the crisis. JFE forthcoming.

Deloitte (2018). The development and evolution of Canadas central counterparty for repo.

Di Maggio, M., A. Kermani, and Z. Song (2017). The value of trading relations in turbulent times. Journal of Financial Economics 124(2), 266-284.

Di Maggio, M. and A. Tahbaz-Salehi (2015). Collateral shortages and intermediation networks. Columbia Business School Research Paper (14-40).

Duffie, D. (2011). Dark markets: Asset pricing and information transmission in over-thecounter markets. Princeton University Press.

Duffie, D. and H. Zhu (2011). Does a central clearing counterparty reduce counterparty risk? The Review of Asset Pricing Studies 1(1), 74-95. 
Ederington, L. H. and J. H. Lee (1993). How markets process information: News releases and volatility. The Journal of Finance 48(4), 1161-1191.

Elliott, M., B. Golub, and M. O. Jackson (2014). Financial networks and contagion. American Economic Review 104(10), 3115-53.

Evans, R. B., C. C. Geczy, D. K. Musto, and A. V. Reed (2009). Failure is an option: Impediments to short selling and options prices. Review of Financial Studies 22(5), 19551980.

Farboodi, M. (2014). Intermediation and voluntary exposure to counterparty risk. Working paper, MIT.

Fleming, M. J. and K. D. Garbade (2005). Explaining settlement fails. Current Issues in Economics and Finance 11(9). Federal Reserve Bank of New York.

Fleming, M. J. and E. M. Remolona (1999). Price formation and liquidity in the U.S. treasury market: The response to public information. The Journal of Finance 54(5), 1901-1915.

Fotak, V., V. Raman, and P. K. Yadav (2014). Fails-to-deliver, short selling, and market quality. Journal of Financial Economics 114(3), 493-516.

Garbade, K. D., F. M. Keane, L. Logan, A. Stokes, and J. Wolgemuth (2010). The introduction of the TMPG fails charge for U.S. Treasury securities. Economic Policy Review (October), 45-71. Federal Reserve Bank of New York.

Glode, V. and C. Opp (2016). Asymmetric information and intermediation chains. American Economic Review 106(9), 2699-2721.

Green, R. C., B. Hollifield, and N. Schürhoff (2007). Dealer intermediation and price behavior in the aftermarket for new bond issues. Journal of Financial Economics 86(3), 643-682.

Hollifield, B., A. Neklyudov, and C. Spatt (2017). Bid-ask spreads, trading networks, and the pricing of securitizations. The Review of Financial Studies 30(9), 3048-3085.

Hugonnier, J., B. Lester, and P.-O. Weill (2018). Frictional intermediation in over-thecounter markets. Working paper, National Bureau of Economic Research.

Khapko, M. and M. Zoican (2019). How fast should trades settle? Management Science forthcoming.

Li, D. and N. Schürhoff (2019). Dealer networks. Journal of Finance 74(1), 91-144.

Liu, H., S. T. McGuire, and E. P. Swanson (2017). The information in naked short sales. Working paper, Texas A\&M University.

Sambalaibat, B. (2018). Endogenous specialization and dealer networks. Working paper, Indiana University.

Stratmann, T. and J. W. Welborn (2012). Exchange-traded funds, fails-to-deliver, and market volatility. Working paper 12-59, George Mason University. 
Table 2: Description of Data

\begin{tabular}{|c|c|c|c|}
\hline Short name & Description & Unit & Source \\
\hline \multicolumn{4}{|c|}{ Bond Variables } \\
\hline REPo SpREad & Target rate less repo rate & bps & CDCC \\
\hline VELOCITY & Securities loan as a share of float & $\%$ & Markit \\
\hline B/A SPREAD & Average daily bid-ask spread & cents & Candeal \\
\hline SPOT MARK-UP & Average dealer markup for spot trades & cents & MTRS \\
\hline REPO MARK-UP & Average dealer markup for repo trades & bps & MTRS \\
\hline FLOAT & Bonds outstanding & Log-\$M & Thomson Reuters \\
\hline AGE & Time since issuance & Years & CDS \\
\hline BENCHMARK & Benchmark status dummy $(2-, 5-, 10-, 30$-year $)$ & {$[0,1]$} & Bank of Canada \\
\hline PRE-BENCHMARK & Pre-benchmark status dummy & {$[0,1]$} & Bank of Canada \\
\hline \multicolumn{4}{|c|}{ Network Variables } \\
\hline COUNTERPARTIES & Number of counterparties in network & & \multirow{6}{*}{ MTRS } \\
\hline LINKS & Number of links in network & & \\
\hline PATHS & Number of paths in network & & \\
\hline AvgPath & Average path length & & \\
\hline DiAMETER & Longest path length & & \\
\hline COMPLEXITY & First principal component of network variables & & \\
\hline \multicolumn{4}{|c|}{ Volume and Fails Variables } \\
\hline Network Volume & Sum of net link volumes & $\$ \mathrm{M}$ & MTRS \\
\hline FAILS & Daily failed volume & $\$ \mathrm{M}$ & CDS \\
\hline \multicolumn{4}{|c|}{ Centrality Variables } \\
\hline IN-DEGREE & Average number of incoming links & & \multirow{7}{*}{ MTRS } \\
\hline OUT-DEGREE & Average number of outgoing links & & \\
\hline EIG-CENTRALITY & Eigenvector centrality & & \\
\hline BETWEENNESS & Betweenness centrality & & \\
\hline Closeness & Closeness centrality & & \\
\hline Clustering & Clustering coefficient & & \\
\hline Centrality & First principal component of centrality variables & & \\
\hline \multicolumn{4}{|c|}{ Other Variables } \\
\hline GC & Bank of Canada target GC rate & bps & Bank of Canada \\
\hline
\end{tabular}

Note: Sources include the Canadian Depository for Securities (CDS); the Canadian Derivatives Clearing Corporation (CDCC); the DEX dataset on Canadian bond yields from FTSE TMX; and the Canadian bond dealers Market Trade Reporting System (MTRS). 


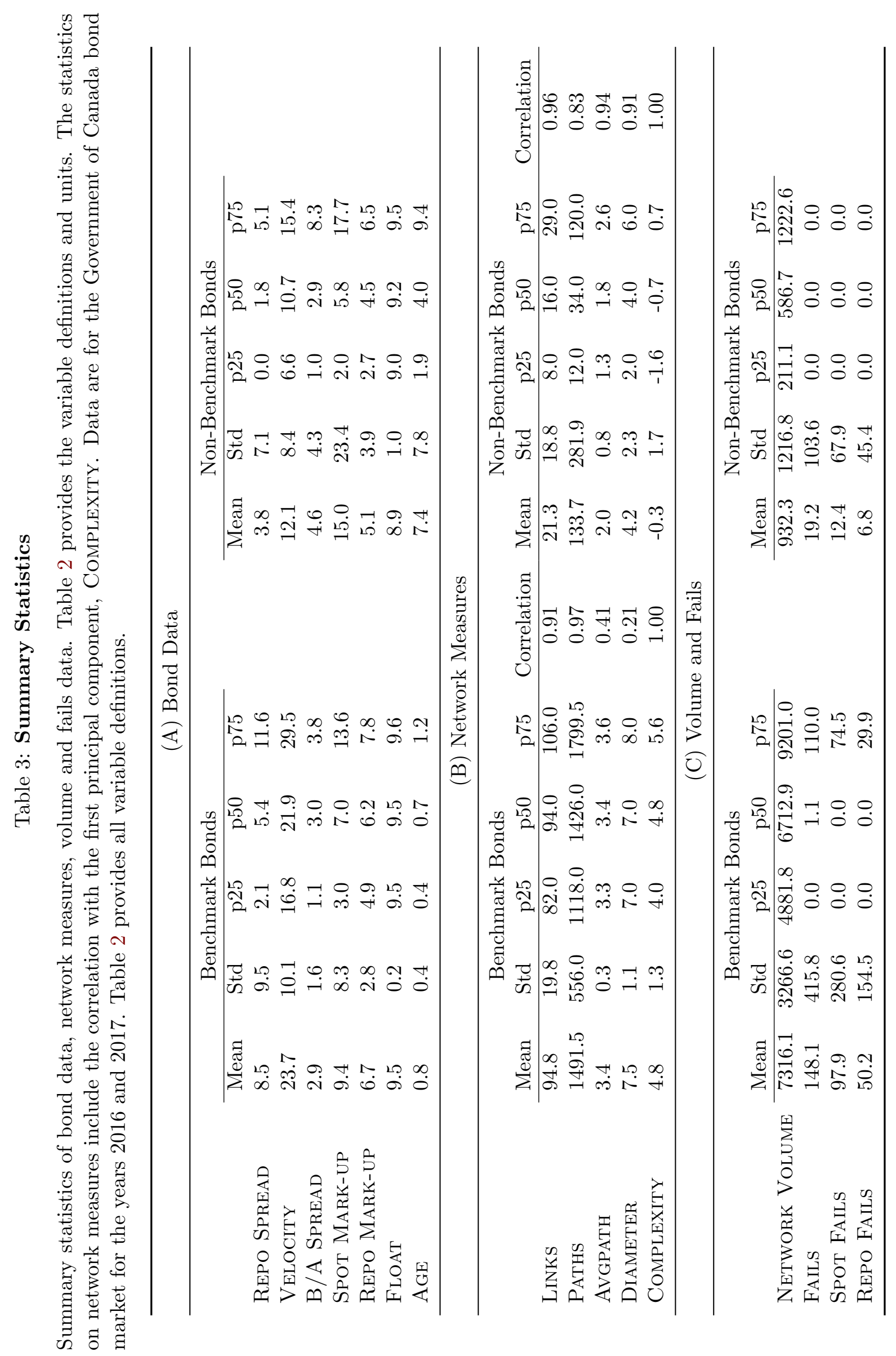




\section{Table 4: Moments of Settlement Fails}

Summary statistics for the fraction of trades that fails, in percentage terms, for the empirical distribution and two simulations. Binomial assumes that settlement fails are independent of each other, with the probability calibrated to the average rate of settlement failure; and the binomial assumes that settlement fails are correlated with the correlation parameter $\rho$ calibrated to match the variance of the settlement fails. We exclude bond-days with fewer than 10 trades. Zeros report the number of bond-days in the sample where there is no failed settlement. Data are for the Government of Canada bond market for Q4 2014 to Q4 2017. Table 2 provides all variable definitions.

\begin{tabular}{llllllll}
\hline & Zeros & Mean & Variance & p75 & p95 & p99 & N \\
Empirical & 12450 & 0.54 & 3.71 & 0.00 & 3.57 & 8.33 & 15013 \\
Beta-binomial $\rho \neq 0$ & 12851 & 0.54 & 3.70 & 0.00 & 3.85 & 9.52 & 15013 \\
Binomial $\rho=0$ & 10831 & 0.54 & 1.70 & 0.42 & 3.08 & 6.25 & 15013 \\
\hline
\end{tabular}

\section{Table 5: Settlement Fails and News}

Quantiles of the change in settlement fails. The change in fails for each bond as the difference in the level of fails on the day prior to the release and the level of fails for the day of the release and the following two days. Panel (A) shows the quantiles for benchmark and non-benchmark bonds. Panel (B) shows the quantiles for bonds with high and low COMPLEXITY, respectively, relative to the median COMPLEXITY value on the day before the news release. ${ }^{* * *}$ and ${ }^{* * *}$ indicate statistical significance at the 10,5 and 1 percent level, respectively, in a test of the null hypothesis that the quantile of the changes is zero. Data are for the Government of Canada bond market for the years 2016 and 2017. Table 2 provides all variable definitions.

Panel (A) Status

\begin{tabular}{|c|c|c|c|c|c|}
\hline \multirow{4}{*}{ Change in Fails } & \multicolumn{5}{|c|}{ Benchmark Bonds } \\
\hline & $\mathrm{p} 50$ & p75 & p90 & p95 & p99 \\
\hline & 0.0 & $31.2^{* *}$ & $210.8^{* * *}$ & $407.0^{* * *}$ & $1965.5^{* * *}$ \\
\hline & \multicolumn{5}{|c|}{ Non-Benchmark Bonds } \\
\hline & $\mathrm{p} 50$ & p75 & p90 & p95 & p99 \\
\hline Change in Fails & 0.0 & 0.0 & $5.4^{* * *}$ & $51.0^{* * *}$ & $259.0^{* * *}$ \\
\hline \multicolumn{6}{|c|}{ Panel (B) Complexity } \\
\hline \multirow{5}{*}{ Change in Fails } & \multicolumn{5}{|c|}{ High Complexity } \\
\hline & $\mathrm{p} 50$ & p75 & p90 & p95 & p99 \\
\hline & 0.0 & $0.2^{*}$ & $56.8^{* * *}$ & $170.4^{* * *}$ & $531.7^{* * *}$ \\
\hline & \multicolumn{5}{|c|}{ Low COMPLEXITY } \\
\hline & $\mathrm{p} 50$ & p75 & p90 & p95 & p99 \\
\hline Change in Fails & 0.0 & 0.0 & 0.0 & $5.0^{* * *}$ & $87.0^{* * *}$ \\
\hline
\end{tabular}




\section{Table 6: News, Dealers Network and Fails - Quantile Regressions}

Quantile regressions of the change in settlement FAILS around news releases at the 95th percentile, including control variables. The independent variable is the change in fails around economic news releases, computed for each bond and for each news release as the difference in the level of fails between the day prior and the day of the news as well as the following two days. AfTer is the baseline increase in these three days. $*^{* *}$ and ${ }^{* * *}$ indicate statistical significance at the 10, 5 and 1 percent level, respectively, in a test of the null hypothesis that the true parameter is zero. Standard errors are clustered by date. Data are for the Government of Canada bond market for the years 2016 and 2017. Table 2 provides all variable definitions.

\begin{tabular}{lcccc}
\hline & $(1)$ & $(2)$ & $(3)$ & $(4)$ \\
AFTER & $215.5^{* * *}$ & 83.6 & $471.0^{* * *}$ & $421.3^{* * *}$ \\
& $(4.35)$ & $(1.39)$ & $(11.2)$ & $(7.91)$ \\
BENCHMARK & & $226.4^{* * *}$ & & 84.5 \\
COMPLEXITY & & $(2.70)$ & & $(1.50)$ \\
NETWORK VOLUME & $3.57^{* * *}$ & 0.48 & -0.51 & -0.78 \\
& $(3.93)$ & $(0.33)$ & $(-0.70)$ & $(-1.07)$ \\
REPO SPREAD & $1010.4^{* * *}$ & $837.8^{* * *}$ & $483.7^{* * *}$ & $509.5^{* * *}$ \\
& $(6.53)$ & $(10.5)$ & $(8.60)$ & $(5.00)$ \\
VELOCITY & $3.93^{* * *}$ & $3.13^{* * *}$ & $0.92^{*}$ & $1.12^{* *}$ \\
B/A SPREAD & $(8.87)$ & $(4.64)$ & $(1.86)$ & $(2.33)$ \\
& $497.5^{* * *}$ & $360.6^{* * *}$ & -15.8 & 37.7 \\
FLOAT & $(5.15)$ & $(3.24)$ & $(-0.29)$ & $(0.57)$ \\
PRE-BENCHMARK & $-22.8^{* * *}$ & -7.86 & $-41.1^{* * *}$ & $-36.6^{* * *}$ \\
& $(-4.60)$ & $(-1.19)$ & $(-10.0)$ & $(-7.29)$ \\
AGE & -13.1 & 20.2 & $-53.1^{* * *}$ & $-49.7^{* * *}$ \\
& $(-0.77)$ & $(0.87)$ & $(-2.92)$ & $(-3.15)$ \\
Observations & $-3.95^{* * *}$ & $-2.16^{* * *}$ & $-2.15^{* * *}$ & $-2.24^{* * *}$ \\
$R^{2}$ & $(-5.72)$ & $(-3.07)$ & $(-5.14)$ & $(-4.62)$ \\
& 5314 & 5314 & 5314 & 5314 \\
& 0.00 & 0.00 & 0.00 & 0.00 \\
\hline
\end{tabular}




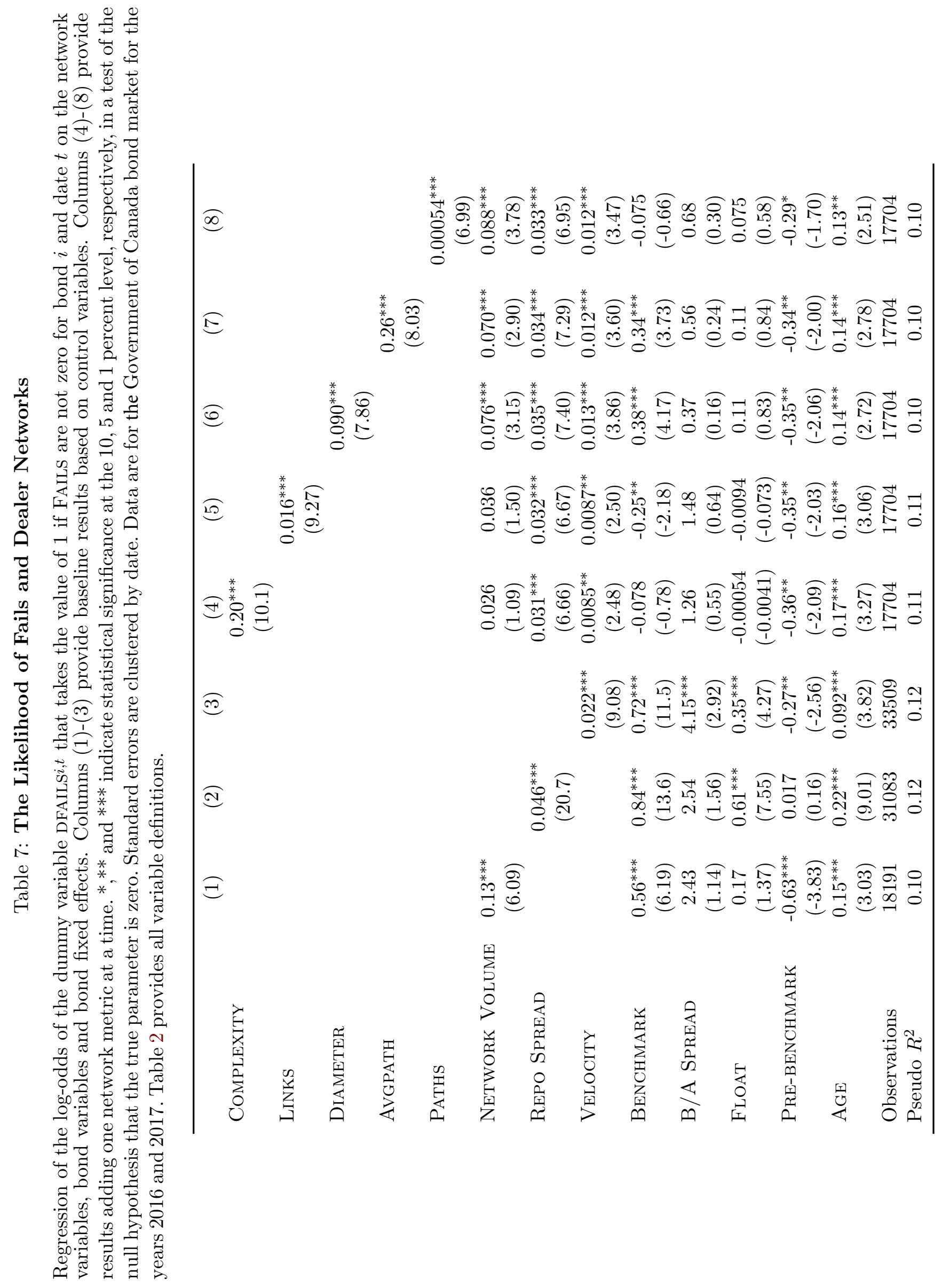




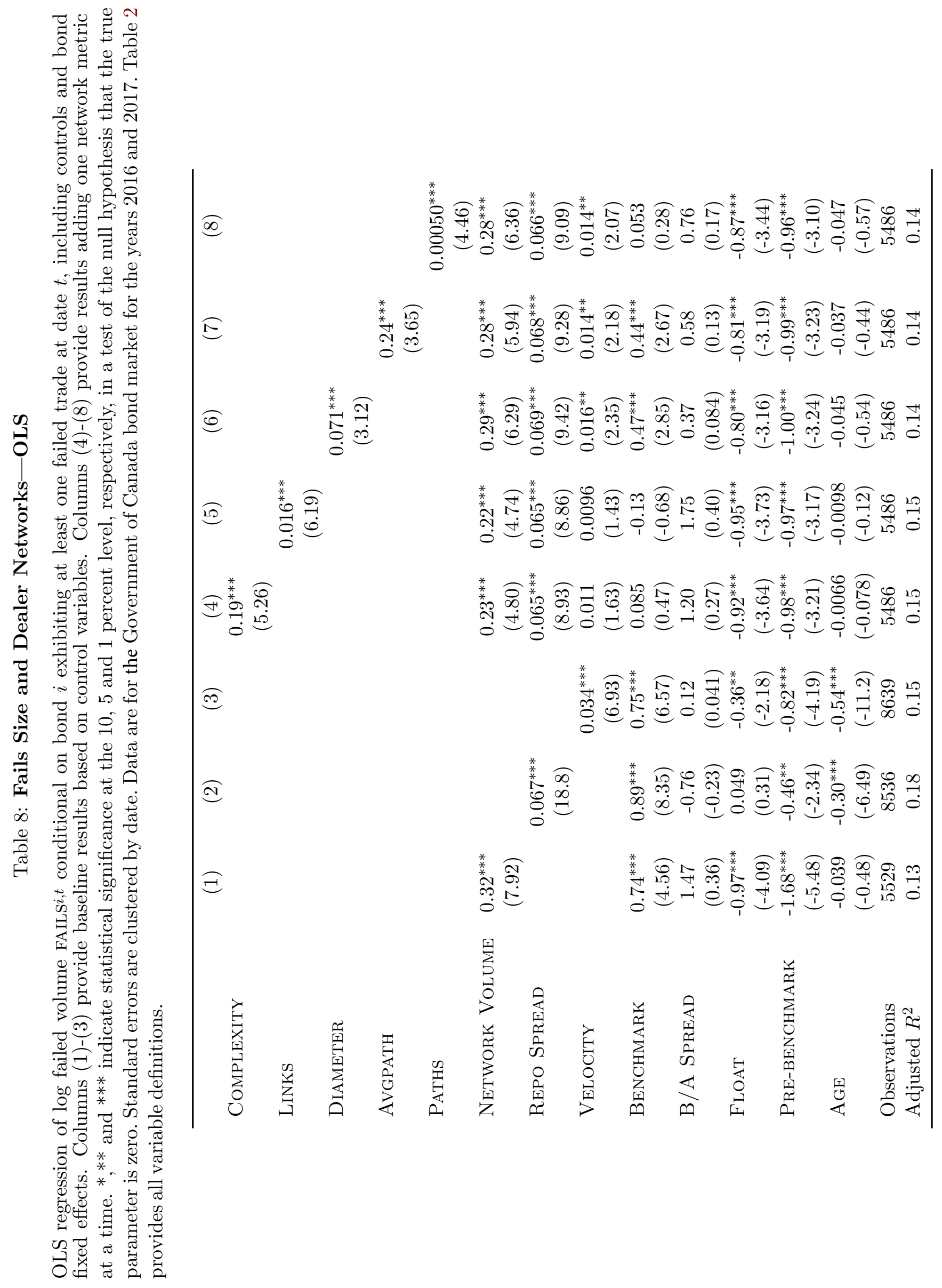




\section{Table 9: Fails Sizes and Dealer Networks-Quantile Regressions}

Quantile regression of FAILS $_{i, t}$ on COMPLEXITYat the 75th, 90th, 95th and 99ht percentiles, including controls as in Table 7 and bond fixed effects. The ${ }^{*}, * *$ and $* * *$ indicate statistical significance at the 10, 5 and 1 percent level, respectively, in a test of the null hypothesis that the true parameter is zero. Standard errors are clustered by date. Data are for the Government of Canada bond market for the years 2016 and 2017. Table 2 provides all variable definitions.

\begin{tabular}{lcccc}
\hline & $\mathrm{p} 75$ & $\mathrm{p} 90$ & $\mathrm{p} 95$ & $\mathrm{p} 99$ \\
CompleXity & $0.15^{* * *}$ & $0.11^{* * *}$ & $0.11^{* * *}$ & $0.080^{* * *}$ \\
& $(3.98)$ & $(3.50)$ & $(3.75)$ & $(2.91)$ \\
Observations & 5487 & 5487 & 5487 & 5487 \\
$R^{2}$ & 0.14 & 0.13 & 0.12 & 0.11 \\
\hline
\end{tabular}




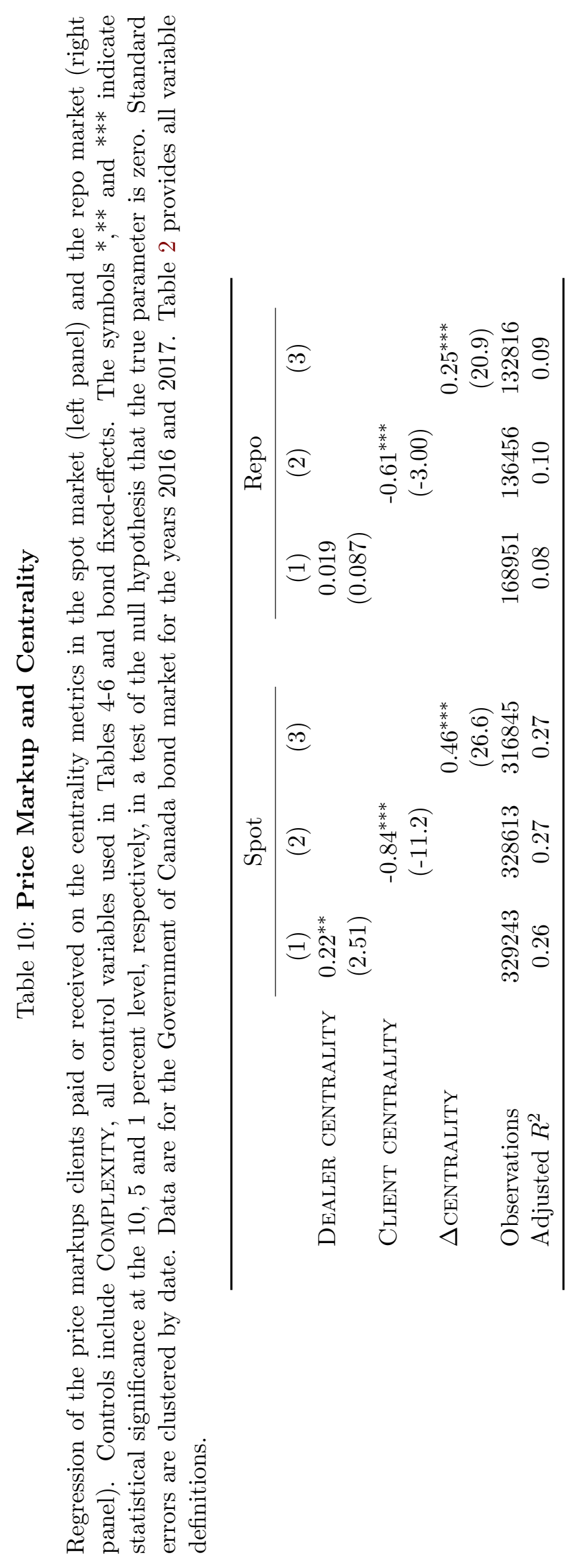




\section{Table 11: Central Clearing Summary Statistics}

Summary statistics of inter-dealer trades in sub-samples defined by the share of transactions centrally. Data are for the Government of Canada bond market for the years 2016 and 2017. Table 2 provides all variable definitions.

\begin{tabular}{lcccc}
\hline & $0 \%-25 \%$ & $25 \%-50 \%$ & $50 \%-75 \%$ & $75 \%-100 \%$ \\
Network Volume & 301.11 & 379.15 & 240.76 & 111.93 \\
REPO SPREAD & 0.03 & 0.04 & 0.04 & 0.03 \\
VELOCITY & 15.37 & 17.29 & 14.48 & 12.24 \\
B/A SPREAD & 0.04 & 0.03 & 0.03 & 0.03 \\
FLOAT & 9.33 & 9.41 & 9.32 & 9.17 \\
AGE & 5.21 & 4.22 & 5.22 & 5.48 \\
Observations & 23098 & 9298 & 6088 & 1896 \\
\hline
\end{tabular}

Table 12: Central clearing and network complexity

Mean of network measures for inter-dealer trades both in the actual data and for the counterfactual where we disconnect the CCP, in the column labelled CCP and No CCP, respectively. The last column reports the difference between the means. The symbols $* * *$ and $* * *$ indicate statistical significance at the 10, 5 and 1 percent level, respectively, in a test of the null hypothesis that difference $\Delta$ is zero. Data are for the Government of Canada bond market for the years 2016 and 2017. Table 2 provides all variable definitions.

\begin{tabular}{|c|c|c|c|}
\hline & $\mathrm{CCP}$ & No CCP & $\Delta$ \\
\hline COMPLEXITY & 0.27 & -0.27 & $0.54^{* * *}$ \\
\hline Counterparties & 6.78 & 6.22 & $0.56^{* * *}$ \\
\hline LINKS & 5.27 & 4.53 & $0.74^{* * *}$ \\
\hline DiAMETER & 2.29 & 1.90 & $0.39^{* * *}$ \\
\hline РAтHS & 11.15 & 8.02 & $3.13^{* * *}$ \\
\hline AvGPATH & 1.39 & 1.25 & $0.14^{* * *}$ \\
\hline Network Volume & 324.21 & 277.99 & $46.22^{* * *}$ \\
\hline
\end{tabular}

